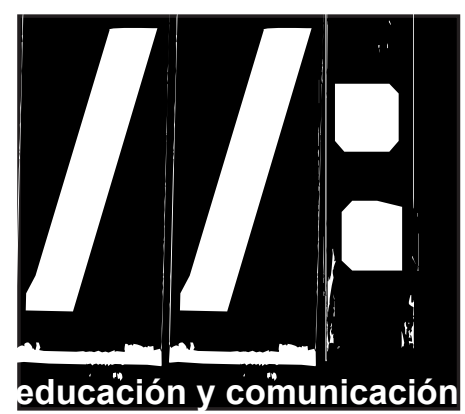

1: 93-97 Nov. 2010

\title{
A PROPÓSITO DEL ABUSO SEXUAL INFANTIL: EN RELACIÓN CON LAS NUEUAS TECNOLOGÍAS E INTERNET
}

\section{tAhout child sexual abuse: in connection with the internet and new technologies]}

\author{
Autores: Ana Pérez López \\ E.mail: apl.anaperez@gmail.com \\ Carlos García Camacho \\ E.mail: cgc@ono.com \\ Alumnos del "Máster en Sexología y Educación Sexual" \\ Universidad de Huelva (España)
}

Resumen:

Un recorrido por lo que entendemos por abuso sexual infantil. Una manera de centrar el tema de algo que nos ocupa y preocupa como ciudadanía e, igualmente, como estudiantes del master en sexología y educación sexual impartido en la Universidad de Huelva. Una forma de acceder a esta temática teniendo como vínculo las relaciones con las nuevas tecnologías e Internet, centrando especial atención al .grooming y cualquier tipo de ciberviolencia, sea a través del correo electrónico, telefonía móvil o las emergentes redes sociales.

Palabras claves: Abusos sexuales, Internet, nuevas tecnologías, grooming, redes sociales

\section{Abstract:}

A way to focus the theme of something that concerns us and concerns such as citizenship and, equally, as students of the master in sexology and sex education at the University of Huelva. A way of accessing this theme as a link having relations with Internet and technology, focusing special attention to. grooming and any ciberviolence, either through e-mail, mobile phone or emerging social networks

Keywords: Sexual abuse, Internet, new technologies, grooming, social networking

(Solicitado: 12-01-10 / Aceptado: 18-10-10)

http://dx.doi.org/10.25267/Hachetetepe.2010.v2.i1.9 
M uy a menudo, encontramos en los periódicos que llegan a nuestras manos, noticias a cerca del abuso sexual infantil. De entrada nos causa rechazo la lectura de dicho artículo. Se trata de leer cómo alguien ha hecho daño a un menor, lo cual no es grato para nadie. Pero, la información que nos aporta, nos puede dar claves de cómo prevenir o detectar esos abusos en nuestro entorno. No hay que rebuscar mucho para saber que estos abusos tienen unas connotaciones que las distingue, tanto por el hecho de que las víctimas son niños, como de que la mayor parte de los agresores se encuentran dentro del círculo que rodea a la familia, es decir, que el agresor es conocido y está integrado en nuestra vida diaria.

Cabe destacar el rechazo que históricamente la sociedad ha tenido ante este tipo de agresiones. Hasta hace pocos años el abuso sexual infantil llegó a considerarse culpa de la propia víctima, hecho éste curioso teniendo en cuenta que se trata de niños y niñas A pesar de la evolución hacia la aceptación de la realidad, no en pocas ocasiones se ha observado la tendencia a ocultar o encubrir los hechos debido entre otras circunstancias a que en su mayoría son realizados por miembros del entorno familiar o cercano, a las graves consecuencias sociales y familiares que acarrean y a las consecuencias en la salud física y sobretodo emocional de los afectados. En España, los estudios epidemiológicos realizados muestran que los abusos infantiles están más extendidos de lo que pensamos y que las consecuencias psicológicas pueden perdurar toda la vida.

¿Qué hacer pues? ¿Cómo podemos evitarlo? ¿Estará mi hijo siendo víctima de un abuso? Vayamos por partes. No podemos esperar que por mucha confianza que los hijos tengan con nosotros nos lo cuenten de manera espontánea, sobre todo teniendo en cuenta la unión afectiva que suelen tener los menores con sus agresores y la relación de confianza que suele haber entre ellos. Por otro lado, la sensación de indefensión a la que están sometidos hace que se encuentren completamente perdidos y que puedan distorsionar la realidad. No olvidemos además que la revelación de los abusos por parte de las víctimas se encuentra con ciertas barreras entre las que están las limitaciones verbales y conceptuales de los niños más pequeños, el miedo al impacto y a la vergüenza, el temor a que no los crean, etc.

Todos sabemos reconocer signos físicos de maltratos (moratones), pero ¿qué ocurre cuando estas evidencias no existen? En este caso es de utilidad conocer cómo podemos, a través del comportamiento de los niños saber si están sufriendo algún tipo de abuso, como pudiera ser el realizar dibujos que muestren actos sexuales, demostrar un interés repentino por lo sexual, juegos sexuados, cambios en los hábitos de sueño, pesadillas, en definitiva, cualquier cambio de comportamiento repentino. Todo esto, dentro de orden lógico, es decir, no porque alguna vez bromeen con sus genitales o cambien su comportamiento quiere decir que están sufriendo un abuso, pero sí sería más alarmante que presentaran varias de estas circunstancias en un periodo de tiempo determinado.

Una manera de prevenir el abuso es fomentar la confianza del niño, de manera que sepan a qué persona dirigirse para manifestar sus temores. Debemos au- 


\section{1/: A propósito del abuso sexual infantil: en relación con las nuevas tecnologías e internet}

mentar su autoestima y demostrar nuestro amor hacia ellos, ya que si el niño se siente amado, no necesitará el cariño simulado de personas que quieran abusar de ellos empleando el afecto como manera de acercamiento. Otro aspecto importante que se debe abarcar en cuanto a prevención, es la educación sexual adecuada a su ciclo evolutivo para integrar en los procesos de aprendizaje del niño el conocimiento y familiarización con su propia identidad corporal, enseñándoles que su cuerpo les pertenece y que cualquier situación o invasión de su intimidad que le incomoda deben comunicarlo a su padre o madre.

Pero no todo el abuso queda dentro de la realidad física. Hoy en día existe un tipo de abuso relacionado con las nuevas tecnologías e Internet. Los niños y adolescentes hoy en día son la primera generación criada en una sociedad en la que la alfabetización tecnológica es esencial para su desarrollo posterior y su futuro. Con el crecimiento de jóvenes, utilizando las tecnologías digitales para fines educativos y recreativos, ha habido un aumento en los problemas sociales en el ciberespacio, exponiéndolos a diferentes formas de ciberviolencia. A medida que crece exponencialmente la comunicación generalizada en este medio, el potencial de delitos relacionados con Internet, tales como el grooming, se ha acelerado. Los niños son particularmente vulnerables a los depredadores sexuales, como los pedófilos, en Internet. El grooming se trata de un acoso ejercido por un adulto con la intención de establecer un control emocional del menor, preparando el terreno para el posterior abuso sexual. No es una nueva forma de abuso, sino la adaptación de la ya existente al nuevo entorno tecnológico, favorecido por el tiempo que pasan los menores conectados a la red y la falta de control por parte de los padres. Por desgracia, cada vez es más común utilizar la autopista de la información para explotar a las víctimas infantiles.

Las herramientas empleadas por los adultos para entrar en contacto con los menores son, entre otras: medios de contacto electrónico (mensajería instantánea, chat, correo electrónico), teléfonos móviles multimedia, uso de redes sociales (Facebook, Twiter). La prevención ante este nuevo tipo de acoso pasa por establecer medidas y normas de uso de internet en casa ("control parental" en el panel de control), y enseñar a los menores una serie de recomendaciones como son:

- No revelar nunca su identidad recurriendo al uso de seudónimos o nicks personales.

- Ser cuidadoso con los datos personales que se publican; estos datos podrán ser utilizados contra el niño.

- Tener especial cuidado a la hora de publicar fotos y vídeos.

- No aceptar ni agregar como contactos a desconocidos

- Evitar el envío de imágenes o vídeos a desconocidos

- Si detectan alguna situación extraña, dar cuenta a los padres.

- Medir la auto-presentación en línea: Es común la utilización de personajes virtuales con una imagen determinada, creadas por los participantes en línea (avatares). Debemos enseñarles a no utilizar una imagen que pueda tener algún grado de provocación. 
Los profesionales del ámbito policial y judicial se enfrentan a diario a dos formas de explotación sexual infantil que parecen estar incrementándose, y a las que merece la pena hacer una mención especial, por la dificultad que presenta su abordaje. Nos referimos a la pornografía infantil en Internet y a la prostitución infantil o tráfico de niños y sexual. En esta línea, proponemos el desarrollo de algunas actuaciones concretas:

- Fomentar la investigación sobre la incidencia real de estas problemáticas para conocer la dimensión del problema a que nos enfrentamos, averiguar si existen grupos de riesgo y poder realizar intervenciones específicas para ellos.

- Sensibilizar y concienciar a la sociedad respecto lo que supone consumir este tipo de servicios y a las redes que lo sustentan.

- Involucrar a los medios de comunicación en esta labor puesto que pueden hacer públicas informaciones relacionadas que alerten a la población u otros tipos de contenidos como podrían ser por ejemplo los nexos de unión existentes entre los países productores y consumidores.

- Desarrollar programas de cooperación y coordinación internacional en el ámbito de la promoción y defensa de los derechos de la infancia que aborden específicamente este tema.

- Penalizar el consumo de pornografía infantil, no sólo su producción o distribución.

- $\quad$ Establecer pautas de control de acceso a las páginas de pornografía infantil dando a conocer a los padres y a la sociedad en general los mecanismos de filtrado de las ya existentes.

- Trabajar con los profesionales del ámbito del turismo para concienciarles de su responsabilidad en el tema del tráfico sexual infantil, estableciendo un código de conducta internacional común para todos los profesionales involucrados.

Además, es sumamente importante el establecimiento de los mecanismos necesarios para una persecución eficaz de los agresores y de las redes internacionales que los amparan. En cuanto a los profesionales implicados en todos estos procesos, existe la necesidad cada vez más, de proporcionarles la formación multidisciplinar que colabore a afrontar y facilitar la atención integral de los niños y niñas víctimas de este tipo de abuso sexual.

Por último, en cuanto a los padres, deben ser conscientes de las maneras en que sus adolescentes se presentan en línea. Se les recomienda involucrarse en el uso que los menores hacen de Internet, instalar los ordenadores en zonas comunes estableciendo un horario de uso, y fomentar la autoprotección (cámaras web, imágenes, vídeos, etc.).

Si a pesar de todas las medidas expuestas, detectamos cualquier tipo de abuso sexual infantil, debemos denunciarlo a las autoridades competentes, al igual que cualquier publicidad o invitación a páginas de pederastia de las que algunas veces asoman a nuestro correo electrónico. En este caso la denuncia debe ser enviada a

www.pornografia.infantil@policia.es.

A todas luces, el presente texto ha sido un pretexto para introducirnos en la problemática del abuso sexual infantil, sin dejar de lado su relación con las 


\section{1/: A propósito del abuso sexual infantil: en relación}

\section{Divulgatio}

nuevas tecnologías e Internet. Una contribución que pretende tomar conciencia de una realidad preocupante.

\section{Webgrafía}

http://chicosymedios.blogspot.com/2009/03/grooming-traves-de-las-tic-un-viejo.html

(Un ejemplo de blog) (Consultada 20 de agosto de 2010)

http://www.uoc.edu/in3/dt/20056/

(Artículo escrito por Fermín Morales Catedrático de Derecho Penal (Universidad Autónoma de
Barcelona) (Consultada 20 de agosto de 2010) http://www.unicef.org/specialsession/ Sesión especial de las Naciones Unidas en favor de la infancia (2002) (Consultada 20 de agosto de 2010) http://www.ecpat.net/EI/Publications/ICT/Cyberspace_SPA.pdf

Informe: La violencia contra los niños en el ciberespacio (Consultada 20 de agosto de 2010) http://www.protegeles.com/

(Página del colectivo Protégeles) (Consultada 20 de agosto de 2010) 